\title{
KAJIAN REPARASI PENGECATAN PADA LAMBUNG KAPAL (STUDI KASUS KM. KIRANA 3)
}

\author{
Zulfaidah Ariany*) \\ Program Studi Diploma Teknik Perkapalan, Fakultas Teknik, Universitas Diponegoro \\ Jl. Prof. Soedarto, SH, Kampus Undip Tembalang, Semarang, Indonesia 50275
}

\begin{abstract}
Abstrak
Kegiatan reparasi kapal adalah hal penting yang harus dilakukan secara rutin dan terjadwal untuk memastikan setiap kapal bisa berlayar dan beroperasi dengan baik sehingga tujuan untuk membawa orang atau mengirimkan barang-barang dapat berjalan lancar. Pengecatan adalah salah satu hal sangat penting pada reparasi lambung kapal. Hal ini dilakukan untuk menghindarkan pelat dari karat atau korosi. Kajian ini dilakukan untuk menghitung konsumsi cat pada kegiatan reparasi lambung kapal dimana hal ini sangat bermanfaat bagi pemilik kapal, bagi galangan pembangun maupun para kontraktor yang berkecimpung pada kegiatan reparasi lambung kapal. Pada kajian ini mengambil studi kasus reparasi lambung pada kapal KM. Kirana 3, dilakukan dengan menghitung/estimasi konsumsi cat yang digunakan, sehingga diperoleh hasil: Kebutuhan cat pada reparasi lambung (pengecatan ulang) KM. Kirana 3 adalah 8 kaleng (20 liter) pada pengecatan di Bottom; 13 kaleng pada daerah Bottop; 42 kaleng pada daerah Topside; serta 6 kaleng pada daerah Weather deck \& Upper deck.
\end{abstract}

Kata kunci: reparasi kapal; pengecatan; korosi; konsumsi cat

\begin{abstract}
[Study on Painting Repair of Hull Ship (Case Study of KM. Kirana 3)] Regular and scheduled maintenance are important things to make sure any ships could work and sail properly. So the main purpose to carry peoples or deliver the goods can be run smoothly. Painting is one of that items. It can protect the body or their parts from rust attack, in common word, corrosion. Estimating the paints consumption upon maintenances are very useful for ship owners, project owners neither shipyards. Upon ship KM. Kirana's hull reparation, an analysis process can calculate the estimation of her paints consumption: For hull paint reparation of KM Kirana 3, it needed estimated 8 cane (20 liter) for bottom painting, 13 canes for bottom top, 42 canes for topside and 6 canes for weather and upper deck.
\end{abstract}

Keywords: ship reparation; painting; corrosion; paint consumption

\section{Pendahuluan}

Perkembangan dunia perkapalan maupun dunia maritim harus diimbangi dengan peningkatan mutu alat transportasi yakni kapal sebagai alat transportasi penghubung utama, pemeliharaan kapal sangat diperlukan agar kapal dinyatakan dalam kondisi yang baik dan layak untuk berlayar. Salah satu pemeliharaan kapal tersebut adalah pengecatan kapal.

Pengecatan kapal berkenaan dengan kualitas dan mutu kapal. Teknik pengecatan dan bahan cat yang baik akan menghasilkan kualitas lambung kapal yang tahan terhadap korosi yang disebabkan oleh air laut dan udara, sehingga kelancaran dan keamanan

\footnotetext{
${ }^{*}$ Penulis Korespondensi.

E-mail: zariany@undip.ac.id
}

kapal dalam menjalankan tugasnya akan berjalan baik. Mengingat kebutuhan tersebut maka pengecatan pada kapal bukanlah kebutuhan tersier ataupun sekunder melainkan kebutuhan primer yang harus dilakukan pada setiap kapal baru ataupun kapal lama dengan mengedepankan hasil yang terbaik.

\section{Rumusan Masalah}

Perlindungan terhadap korosi pada kapal dengan metode pengecatan serta tahap-tahap dalam pengecatan kapal tersebut, karena hampir semua material penyusun kapal adalah logam maka perlindungan badan kapal dari korosi dengan cara pengecatan (coating). Agar hasil pengecatan memenuhi syarat-syarat yang telah ditentukan, maka harus sesuai prosedur pengecatan yang telah ditentukan. Untuk itu, kita perlu mengetahui tentang teknik-teknik pengecatan serta berbagai macam 
persiapan yang harus dilakukan sebelum dilaksanakan proses pengecatan badan kapal. Mengingat daerah kerja kapal adalah di laut maka sifat logam reaktif terhadap korosi. Adapun masalah yang akan dibahas pada makalah ini yaitu:

Berbagai jenis pengecatan kapal yang dilakukan pada saat reparasi lambung; Kebutuhan Cat diperlukan pada saat reparasi lambung kapal KM. Kirana; serta menghitung kebutuhan cat dan pembagian daerah pengecatan pada proses pengecatan lambung kapal KM. Kirana 3 tersebut.

\section{Tujuan dan Manfaat}

Tujuan dari kajian penulisan/penelitian ini adalah menjawab rumusan masalah yang telah disusun, sedangkan manfaat dari penulisan makalah ini adalah untuk:

- Menghitung kebutuhan cat di kegiatan pengecatan kapal pada reparasi lambung kapal.

- Memberikan informasi mengenai pengendalian terhadap korosi dengan cara metode pengecatan.

- Sebagai bahan informasi dan pembelajaran bagi pihak yang ingin mengetahui dan mendalami tentang pengecatan kapal sekaligus sebagai referensi bagi pihak yang membutuhkan.

\section{Kajian Teori}

Pengecatan badan kapal berguna untuk melindungi kulit kapal dari proses pengkaratan dan juga binatang laut, karena hampir semua material penyusun kapal adalah logam (pelat baja). Mengingat daerah kerja kapal adalah di laut maka sifat logam (pelat baja) reaktif terhadap korosi. Sebelum melakukan pengerjaan pengecatan terlebih dahulu material yang akan dicat harus bersih dari kotorankotoran minyak maupun sisa-sisa cat dan debu. Karena apabila dilakukan sandblasting membutuhkan biaya yang cukup mahal apalagi pengecatan harus dilakukan seperti bangunan baru, maka proses pembersihan dari kotoran tersebut harus benar-benar bersih. Sebelum mulai pengecatan maka kapal dibersihkan terlebih dahulu dengan tujuan menghilangkan kotoran-kotoran yang menempel pada kapal. Kapal sebagai alat transportasi air, maka dari itu sangat rentan terhadap kerusakan yang diakibatkan oleh air (korosi dan lapuk) maupun tumbuhan atau binatang laut yang menempel pada badan kapal yang tercelup air.

Korosi adalah peristiwa turunnya kemampuan material logam menerima beban, sebagai akibat terjadinya peristiwa oksidasi dengan lingkungan yang mengalami penipisan material dari konstruksi. Peristiwa korosi terjadi karena peristiwa alami (Natural Process) reaksi elektro kimia, setiap logam yang memiliki laju korosinya masing-masing dan adanya lapisan pasif (Passive Layer) pada permukaan logam tersebut. Korosi dapat diartikan juga sebagai lapisan-lapisan hasil reaksi dari logam terhadap lingkungan yang mengelilinginya. Dan korosi dapat dikelompokkan kedalam korosi basah dan korosi kering. Korosi basah disebabkan oleh karena lingkungan yang mengelilinginya mengandung larutan atau pelarut. Ini direferensikan pada sebagian besar kejadian korosi pada temperatur lingkungan. Pada sisi lain korosi kering dihasilkan oleh reaksi kimia dari gas dalam temperatur tinggi. Salah satu metode yang paling banyak digunakan dalam menanggulangi korosi, pelapukan, maupun binatang dan tumbuhan laut yang terbukti efektif adalah pengecatan (protective coatings). Komponen utama dalam pengecatan ini yaitu cat. Cat merupakan suatu bahan cair atau bahan kental yang terdiri dari hantaran medium (vehicle) yang merupakan bahan cair dari bahan cat itu sendiri. Bahan pewarna dan bahan penunjang (partikel yang kecil dan tidak larut dengan hantaran medium), ditambah dengan beberapa bahan tambahan dalam jumlah tertentu, sesuai campuran dan takarannya.

Pencampuran berbagai jenis bahan baku dengan jumlah dan proporsi tertentu menjadi satu kesatuan, dengan pengawasan laboratorium produksi yang ketat dari tahap awal hingga menghasilkan produk cat yang siap pakai.

Untuk mendapatkan hasil pengecatan yang baik dan berkualitas maka pihak yang terkait dalam pengecatan perlu mengetahui dasar-dasar pengecatan baik teknis aplikasi maupun pengawasan sehingga perlakuan dan penanganan dapat dilakukan sedemikian rupa untuk memenuhi spesifikasi baik oleh aplikator pemilik inspektor atau konsultan sehingga selama proses pengecatan diharapkan dapat meningkatkan hasil kerja dan kualitas secara efisien.

Perlindungan pelat dari korosi dapat dilaksanakan dengan pengecatan, dimana pengecatan sesuai peraturan-peraturan pengecatan untuk kapal. Sebelum diadakan pengecatan, persiapan memegang peranan penting terhadap hasil pengecatan. Pelat yang akan dicat harus bersih dari karat-karat, minyak, dan kotoran akibat oksidasi lainnya dan sebelum pengecatan harus sesuai rencana kegiatan (painting schudule) baik cara pengecatan maupun waktu pengeringan yang dibutuhkan, terutama yang harus diperhatikan adalah pada tempat-tempat pengelasan dan bekas-bekas pekerjaan yang mengandung minyak/graise.

Pelaksanaan pengecatan dapat dilakukan dengan menggunakan roll, kuas, ataupun menggunakan semprot. Macam-macam cat yang digunakan untuk mengecat kapal adalah:

- Untuk badan kapal bagian bawah (keel) sampai dengan bottom digunakan cat anti corrosion (AC). Cat AC berguna untuk melindungi badan kapal dari pengkaratan.

- Selanjutnya diadakan pengecatan dengan cat anti fouling (AF) untuk mencegah menempelnya hewan dan tumbuhan laut.

\section{Proses dan Metode Pengecatan}

Beberapa metode dan proses pengecatan yang perlu diketahui (Aulia,dkk 2014): 
- Pre Inspection

Pre inspection merupakan awal terhadap permukaan material yang akan di cat dengan tujuan agar diperoleh perekatan secara maksimal untuk proses pengecatan atau painting.

- Surface Preparation

Pekerjaan utama yang dilakukan pada tahap ini adalah blasting, dengan kegunaan utama menghilangkan kontaminasi atau pencemaran dari dasar menghapus rekat erat, nahan kimia, kotoran dsb serta berguna untuk menyiapkan permukaan dengan jalan menaikkan tingkat kekasaran sehingga pengecatan menjadi efektif

- Paint Preparation

Paint preparation merupakan tahapan persiapan sebelum dilakukan painting, menyiapkan peralatan painting dan painter, proses mixing yaitu pencampuran cat

- Paint Application

Setelah proses pengecatan harus dilakukan pemeriksaan terhadap hasil pengecatan.

\section{Urutan Pengecatan}

Pada saat pengecatan badan kapal, urutan pelapisan cat harus diperhatikan. Hal ini mengingat tiap-tiap lapisan cat menggunakan jenis cat yang berbeda.

a. Lapisan pertama

Pada lapisan pertama, jenis cat yang dipakai adalah jenis cat dasar. Fungsi cat dasar adalah untuk melindungi permukaan logam agar tidak berkarat atau rusak.

b. Lapisan Kedua

Pada lapisan kedua, jenis cat yang digunakan adalah jenis cat Anti Corrosion (AC), berfungsi sebagai penebal agar serangan yang datang dari luar (excess) dapat dicegah dan untuk mencegah terjadinya korosi.

c. Lapisan Ketiga

Pada lapisan ketiga atau lapisan terluar, jenis cat yang digunakan adalah jenis cat Anti Fouling (AF). Cat jenis ini berfungsi untuk mencegah binatang laut agar tidak menempel pada badan kapal.

\section{Cara-Cara Pengecatan}

Pengecatan dengan menggunakan kuas atau roll (konvensional). Cara kerjanya dengan mengolesi badan kapal dengan kuas atau roll. Sedangkan cara kedua adalah pengecatan dengan menggunakan kompressor (modern). Cara kerjanya dengan kompressor diberi tekanan yang tinggi untuk menyemprotkan cat pada badan kapal.

\section{Jenis Pengecatan Kapal dan Perbedaannya}

Pengecatan kapal bangunan baru, meliputi pengecatan keseluruhan badan kapal dari haluan hingga buritan termasuk sistem dalam kapal. Sedangkan pengecatan kapal repair, pengecatan kapal hanya pada bagian tertentu yang sesuai peraturan harus dilakukan pengecatan kembali setelah beberapa waktu. Selanjutnya pada kajian ini hanya membahas tentang pengecatan pada kapal repair.

Langkah sebelum pengecatan: Lambung kapal disemprot dengan air tawar, dilakukan penyekrapan, pengetokan, sandblasting selanjutnya dilakukan pengecatan

\section{Penggunaan Cat}

Dalam pengecatan penggunaan cat berbedabeda dikarenakan cat itu sendiri memiliki fungsi berbeda, penggunaan cat antara lain:

- Cat Primer (P), yaitu cat dasar, merupakan lapisan pertama berlangsung pada permukaan pelat. Cara ini berfungsi untuk menutup pori-pori pelat dan sekaligus sebagai daya scrap atau lekat dengan lapisan berikutnya.

- Cat Anti Corrosion (AC), cat ini mempunyai sifat menahan oksidasi sehingga menahan korosi pada pelat. Biasanya digunakan pada lapisan kedua setelah cat primer.

- Cat Anti Fouling (AF), cat ini mempunyai sifat mengurangi daya tempel dan mematikan binatang laut, sehingga mengurangi banyaknya binatang laut yang menempel pada waktu berlabuh. Cat ini dipergunakan pada bagian kapal pada antara lunas sampai dengan garis air. Dimana pada bagian ini selalu tercelup air dan sangat mungkin ditempel binatang laut.

- Cat Bottop $(\mathrm{B} / \mathrm{T})$, cat Bottop yaitu cat yang mempunyai daya korosif yang tinggi dan merupakan lapisan setelah anti korosi. Cat ini dipergunakan pada daerah antara garis muat kosong dan garis muat penuh. Dimana pada daerah ini merupakan daerah yang sangat mungkin terjadi korosi karena selalu terjadi perubahan antara tercelup air dan terkena udara.

- $\quad$ Cat Top Side (T/S), cat ini dipergunakan untuk cat akhir (finished paint) yang dipergunakan dibagian kapal diatas garis air penuh dan warnanya harus disesuaikann dengan warna kapal.

- Cat Deck, yaitu cat yang dipergunakan untuk mengecat deck, selain yang ada pada daerah tertentu misalnya: Halt paint digunakan untuk palkah, funnel digunakan untuk cerobong.

- Cat Bitominious, yaitu cat khusus untuk bagian jangkar, rantai jangkar dan chain locker (kotak jangkar)

\section{Bagian Pengecatan Kapal}

- Pengecatan pada daerah Top side menggunakan Cat Primer (P), Cat Anti Corrosion (AC), Cat Top Side (T/S).

- Pengecatan pada daerah Bottop menggunakan Cat Primer (P), Cat Anti Corrosion (AC), Cat Bottop $(\mathrm{B} / \mathrm{T})$.

- Pengecatan pada daerah Bottom menggunakan Cat Primer (P), Cat Anti Corrosion (AC), Cat Anti Fouling (AF) (Kusna, 2008) 


\section{Metode Penelitian}

Dalam kajian mengenai pengecatan pada kapal ini dilakukan :

\section{TOP SIDE \\ BOTTOM TOP \\ BOTTOM}

\section{Gambar 1. Pembagian daerah pengecatan}

- Metode tinjauan langsung, melihat langsung bagaimana proses dan cara pengecatan dilakukan oleh para pekerja di galangan, khususnya pada kapal KM. Kirana 3

- Metode Interview, terhadap pihak galangan dan pihak lain yang berkompeten terhadap masalah tersebut dan mengajukan pertanyaan kepada pekerja di PT. Janata Marina Indah Semarang tentang segala sesuatu yang berkaitan dengan penelitian ini.

- Metode kepustakaan dengan membaca sumbersumber referensi yang memiliki hubungan pengecatan pada kapal.

\section{Hasil dan Pembahasan}

\section{Cara pengecatan pada badan kapal}

Dalam pengecatan pada badan kapal harus memiliki metode atau cara yang diaplikasikan pada langkah kerja dan cara pengecatan kapal, diantaranya:

a. Pengecatan kapal dengan Cara Conventional

Metode conventional adalah metode yang sederhana dimana alat yang digunakan berupa rol dan kuas. Tetapi metode ini hanya dapat digunakan pada daerah-daerah tertentu seperti pada bagian-bagian batasan dua cat, bagianbagian yang sulit dijangkau, dan pada bagianbagian yang rata. Cara pengecatannya adalah dengan mengolesi badan kapal menggunakan kuas atau rol secara vertikal maupun horizontal. Metode ini memiliki keuntungan; menghemat pemakaian cat, tidak membutuhkan tenaga ahli, dapat menjangkau tempat-tempat yang sulit serta memiliki ketebalan cat yang baik. Namun kerugian bila menggunakan metode konvensional, antara lain adalah membutuhkan waktu pengecatan yang lama serta hasil pengecatan kurang baik (kurang rata).

b. Pengecatan kapal dengan Cara Mekanik

Pengecetan dengan cara ini sangatlah baik hasilnya, karena cat yang dikeluarkan dari nozzle bertekanan tinggi dengan demikian mempunyai daya serap dan tingkat kerataan yang tinggi ke dalam pelat baik dalam posisi pengecatan yang sulit pun bisa terjangkau, sehingga baik untuk proses pengecatan pada lapis pertama. Bila pengecatan dengan cara ini maka cat harus diencerkan terlebih dahulu. Kecepatan sangat baik dan dapat menghemat waktu, pengecetan adalah bagian dari system produksi merupakan salah satu komponen yang dapat memberikan konstribusi dalam meningkatkan koefesien.

\section{Menghitung kebutuhan cat}

Dalam proses pengecatan ini, tentu sangat diperlukan untuk menghitung konsumsi atau jumlah cat yang harus digunakan pada proses pengecatan. Hal ini dimaksudkan agar kebutuhan cat dapat diperhitungkan dan tentu untuk menghitung besarnya biaya untuk memenuhi kebutuhan cat ini.

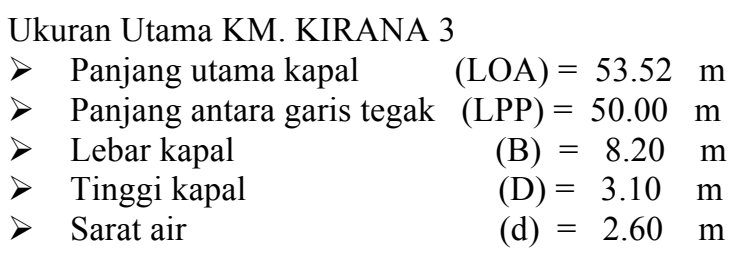

Kebutuhan Cat pada KM. Kirana 3

a. Pengecatan pada daerah Bottom (incl. Bootop) : Dengan rumus perhitungan: (Kusna, 2008)

$$
\begin{aligned}
& \mathrm{A}=((2 \times \mathrm{d})+\mathrm{B}) \times \operatorname{LPP} \times \mathrm{P}\left(\mathrm{m}^{2}\right), \text { dimana } \\
& \mathrm{d}=\text { sarat air } \\
& \mathrm{B}=\text { lebar kapal } \\
& \text { Lpp }=\text { panjang antara garis tegak } \\
& \mathrm{P}=0.70-0.75 \text { untuk cargo barang } \\
& \text { Diperoleh Luasan : } \quad \mathrm{A}=496.47 \mathrm{~m}^{2}
\end{aligned}
$$

Maka luas total

$\begin{aligned} \text { Cat } \mathrm{AC}=2 \text { kali pengecatan } & =2 \times 496.47 \mathrm{~m}^{2} \\ & =993.48 \mathrm{~m}^{2} \\ \text { Cat } \mathrm{AF}=1 \text { kali pengecatan } & =1 \times 496.47 \mathrm{~m}^{2} \\ & =496.47 \mathrm{~m}^{2}\end{aligned}$

Kebutuhan total cat pada daerah bottom adalah $10 \mathrm{~m}^{2}$ menghabiskan 1 liter cat maka :

Cat $\mathrm{AC}=993.48 \mathrm{~m}^{2}$ maka menghabiskan $=993.48$

$$
/ 10=99.34 \text { liter }
$$

Cat $\mathrm{AF}=496.47 \mathrm{~m}^{2}$ maka menghabiskan $=496.47 / 10$ $=49.64$ liter.

Kebutuhan cat AC dan AF pada KM KIRANA 3 pada cat $\mathrm{AC}+$ Cat $\mathrm{AF}=$ kebutuhan total. 99,34 + $49,64=148,99$ liter. Untuk 1 kaleng cat besar 20 liter maka 148,99/20 =7,4 kaleng

b. Pengecatan pada daerah Bottop

Dengan rumus perhitungan :
A $\quad=2 \times \mathrm{hx}(\mathrm{Lpp}+0,5 \times \mathrm{B})\left(\mathrm{m}^{2}\right)$ Dimana:
$\mathrm{h}=$ lebar dari boottop
B = lebar kapal
Lpp = panjang antara garis tegak 


$$
\begin{aligned}
& \text { Dengan Perhitungan : } \quad A=876.42 \mathrm{~m}^{2} \\
& \text { Maka luas total } \\
& \begin{aligned}
\text { Cat } \mathrm{AC} & =2 \text { kali pengecatan }=2 \times 876.42 \mathrm{~m}^{2} \\
& =1752.84 \mathrm{~m}^{2}
\end{aligned} \\
& \begin{aligned}
\text { Cat AF } & =1 \text { kali pengecatan }=1 \times 876.42 \mathrm{~m}^{2} \\
& =876.42 \mathrm{~m}^{2}
\end{aligned}
\end{aligned}
$$

Jika kebutuhan total cat pada daerah bottop adalah 10 $\mathrm{m}^{2}$ menghabiskan 1 liter cat maka :

$$
\begin{aligned}
\text { Cat } \mathrm{AC} & =1752.84 \mathrm{~m}^{2} \text { maka menghabiskan } \\
& =1752.84 / 10=175.28 \text { liter } \\
\text { Cat } \mathrm{AF} & =876.42 \mathrm{~m}^{2} \text { maka menghabiskan } \\
& =876.42 / 10 \quad=87.64 \text { liter }
\end{aligned}
$$

Kebutuhan cat AC dan AF pada KM KIRANA 3 Cat $\mathrm{AC}+\mathrm{Cat} \mathrm{AF}=$ kebutuhan total $175.28+87.64=$ 262.92 liter.

Untuk 1 kaleng cat besar 20 liter, maka 262.92/20= 13 kaleng

c. Pengecatan pada daerah Top side Dengan rumus perhitungan,

$$
\begin{aligned}
& \mathrm{A}=2 \times \mathrm{H} \times(\text { Loa }+0,5 \times \mathrm{B})\left(\mathrm{m}^{2}\right) \text { Dimana } \\
& \mathrm{H}=\text { tinggi topsides }(\text { depth }- \text { draught }) \\
& \mathrm{B}=\text { lebar kapal kapal } \\
& \text { Loa }=\text { Panjang utama kapal }
\end{aligned}
$$

Perhitungan:

$$
\mathrm{A}=2 \times \mathrm{x} \mathrm{x}(\mathrm{Loa}+0,5 \times \mathrm{B})=2764.200 \mathrm{~m}^{2}
$$

Maka luas total:

Cat $\mathrm{AC}=2$ kali pengecatan $=2 \times 2764.200 \mathrm{~m}^{2}$ $=5528.40 \mathrm{~m}^{2}$

Cat $\mathrm{AF}=1$ kali pengecatan $=1 \times 2764.200 \mathrm{~m}^{2}$ $=2764.20 \mathrm{~m}^{2}$

Kebutuhan total cat pada daerah top side adalah 10 $\mathrm{m}^{2}$ menghabiskan 1 liter cat maka :

Kebutuhan cat AC dan AF pada KM KIRANA 3 pada $\mathrm{Cat} \mathrm{AC}+\mathrm{Cat} \mathrm{AF}=$ kebutuhan total. 552.84 $+276.42=829,26$ liter.

Pengecatan daerah Top Side yakni $8292.6 \mathrm{~m}^{2}$ dengan menghabiskan 829,26 liter cat, untuk 1 kaleng cat besar 20 liter, maka 829/20=42 kaleng

d. Pengecatan weather deck dan upper deck Dengan rumus perhitungan :

$$
\begin{array}{ll}
\mathrm{A} & =\text { Loa } \times \mathrm{B} \times \mathrm{N} \text { Dimana } \\
\mathrm{B} & =\text { lebar kapal } \\
\mathrm{LOA} & =\text { Panjang utama kapal } \\
\mathrm{N} & =0.88 \text { untuk cargo liners }
\end{array}
$$

Perhitungan: $\quad \mathrm{A}=$ Loa $\mathrm{x} \mathrm{B \times} \mathrm{N}=386.2 \mathrm{~m}^{2}$

$$
\text { Maka luas total }
$$

$$
\begin{aligned}
\text { Cat } \mathrm{AC} & =2 \text { kali pengecatan }=2 \times 386.2 \mathrm{~m}^{2} \\
& =772.4 \mathrm{~m}^{2} \\
\text { Cat } \mathrm{AF} & =1 \text { kali pengecatan }=1 \times 386.2 \mathrm{~m}^{2} \\
& =386.2 \mathrm{~m}^{2}
\end{aligned}
$$

Kebutuhan total cat pada daerah weather deck dan upper deck adalah $10 \mathrm{~m}^{2}$ menghabiskan 1 liter cat maka :

Cat $\mathrm{AC}=772.4 \mathrm{~m}^{2}$ maka menghabiskan $=772.4 / 10=$ 77.24 liter
Cat $\mathrm{AF}=386.2 \mathrm{~m}^{2}$ maka menghabiskan $=386.2 / 10=$ 38.62 liter

Kebutuhan cat AC dan AF pada KM KIRANA 3 pada cat $\mathrm{AC}+\mathrm{Cat} \mathrm{AF}=$ kebutuhan total. 77.24 $+38.62=115.86$ liter, maka pengecatan daerah weather deck dan upper deck yakni $1158.6 \mathrm{~m}^{2}$ Dengan menghabiskan 115.86 liter cat. Untuk 1 kaleng cat besar 20 liter, maka kebutuhan adalah $115 / 20=6$ kaleng

\section{Cacat Pengecatan dan Cara Perbaikannya}

Cacat pengecatan merupakan hal yang tidak dapat dihindari namun dapat diminimalkan sekecil mungkin dengan memperhatikan ergonomi pengecatan dan persiapan pengecatan yang baik. Berikut faktor yang harus diperhatikan agar pengecatan badan kapal dapat berjalan dengan baik dengan hasil yang baik. Hal yang bisa dilakukan antara lain: Kontrol peralatan dalam keadaan standar, pembersihan benda yang akan di coating (substrate) agar sesuai standar, melakukan pengampelasan dengan baik dan benar, mengaduk coating dengan seksama dan sampai homogeny, menggunakan thinner yang direkomendasikan, memperhatikan tekanan dan kecepatan angin agar sesuai standar, menggunakan prosedur pengecatan yang baik serta mentaati peraturan $\mathrm{K} 3$.

\section{Kesimpulan}

Kegiatan pemeliharaan kapal harus dilakukan secara berkala agar kapal layak untuk berlayar dan dapat memperlancar transportasi laut. Didalam pemeliharaan kapal diantara lainnya yang sangat penting yakni pemeliharaan pengecatan kapal untuk perawatan kapal terhadap korosi yang sangat membahayakan bila diabaikan.

Penggunaan cat pada bangunan kapal juga tidak sembarangan, dibutuhkan spesifikasi untuk cat tersebut diantaranya seperti Cat Primer (P) yang merupakan cat dasar dan sebagai lapisan pertama pada permukaan pelat. Cat Anti Corrosion (AC), cat ini mempunyai sifat menahan oksidasi sehingga menahan korosi pada pelat. Cat Anti Fouling (AF) Cat ini mempunyai sifat mengurangi daya tempel dan mematikan binatang laut. Cat Bottop (B/T) Cat Bottop yaitu cat yang mempunyai daya korosif yang tinggi dan merupakan lapisan setelah cat AC. Cat Top Side (T/S) Cat ini dipergunakan untuk cat akhir (finished paint) yang dipergunakan dibagian kapal diatas garis air penuh dan warnanya harus disesuaikann dengan warna kapal. Deck Paint yaitu cat yang dipergunakan untuk mengecat deck.

Kebutuhan cat pada reparasi lambung (pengecatan ulang) KM.Kirana 3 adalah 8 kaleng (20 liter) pada pengecatan di Bottom; 13 kaleng pada daerah Bottop; 42 kaleng pada daerah Topside; serta 6 kaleng pada daerah Weather deck \& Upper deck.

Kajian ini bisa dilanjutkan lagi dengan menganalisa secara ekonomi pengecatan yang dilakukan pada reparasi lambung kapal, kajian secara 
Teknik, 35 (1), 2014, 32

lebih lengkap akan sangat membantu para pemilik kapal untuk mengatur dan menghitung biaya-biaya yang harus dilakukan/ dikeluarkan pada saat reparasi. Mengingat pentingnya proses pengecatan ini, maka sangat disarankan agar para operator pengecatan harus orang-orang yang telah terlatih dalam hal pengecatan badan kapal, agar hasil pengecatan maksimal. Pelayanan jasa yang diberikan instansi galangan harus selalu ditingkatkan khususnya pada mutu agar tercapainya kepuasan para pelanggan dan atau pemakai jasa instansi galangan.

\section{Daftar Pustaka}

Aulia Windyandari, Ahmad FZ, Sarwoko. (2014). Studi Perbandingan Metode Pelapisan (Coating) pada Ruang Muat Berbasis Regulasi IMO; Jurnal Teknik Vol. 34 No. 3 ISSN 08521697; Semarang

Djatmiko, S, Soedijono, Soedarsono. (1983). Teknik Galangan Kapal dan Dock Jilid I dan Jilid II. Jakarta: Departemen Pendidikan dan Kebudayaan, Direktorat Jenderal Pendidikan Dasar dan Menengah.

Fakultas Teknik Kelautan. (1978). Diklat Konstruksi Kapal Baja Jilid II. Jakarta: Departemen Pendidikan dan Kebudayaan, Direktorat Jenderal Pendidikan Dasar dan Menengah.

Kusna, Indra Djaya. (2008). Teknik Konstruksi Kapal Baja Jilid II. Jakarta: Departemen Pendidikan dan Kebudayaan, Direktorat Jenderal Pendidikan Dasar dan Menengah.

Wawan Setiawan. (2013). Laporan Kerja Praktek pada PT. JMI Semarang, Semarang. 